\title{
Der „Vater der Immuntherapie"
}

"Jedem Anfang wohnt ein Zauber inne“ schrieb Hermann Hesse in seinem Gedicht „Stufen“. Diesen Zauber muss William B. Coley verspürt haben, nachdem er 1891 einem Patienten mit inoperablem Tumor Streptokokken-Organismen injiziert hatte. Denn: Der Tumor bildete sich zurück. Der Sarkomchirurg entwickelte im Zuge seiner Studien das nach ihm benannte Coley-Toxin, eine Mischung aus Bakterienstämmen. Zeit seines Lebens verfolgte er die Theorie weiter, dass Tumoren durch Infektionen und die dadurch induzierte Reaktion des Immunsystems bekämpft werden können. Zu Lebzeiten erntete er hierfür viel Kritik. Heute gilt er als der "Vater der Immuntherapie“.
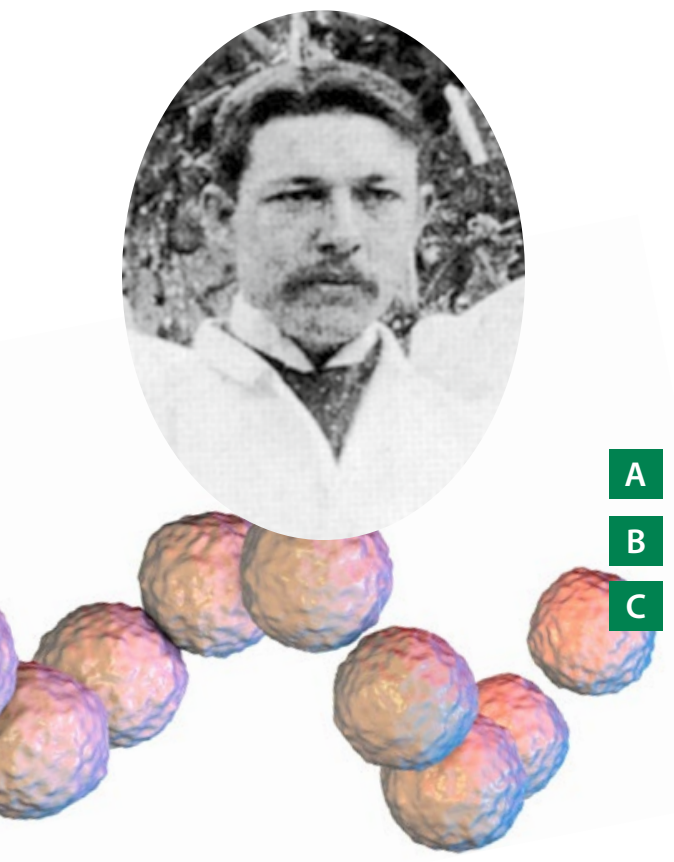

Aus welchen Bakterienstämmen setzte sich das Coley-Toxin zusammen?

A Streptococcus pyogenes und Serratia marcescens

B Streptococcus pneumoniae und Serratia marcescens

Streptococcus pyogenes und Escherichia coli
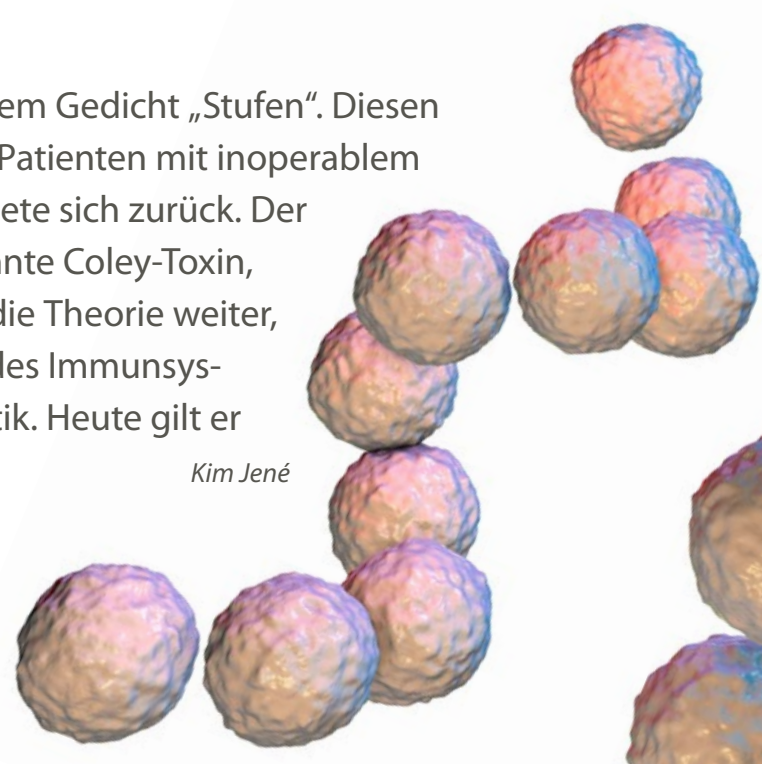

Durch Ihre Teilnahme am Quiz erklären Sie sich damit einverstanden, dass im Falle eines Gewinns Ihr Name plus Wohnort an dieser Stelle veröffentlicht wird.

Der Buchstabe der richtigen Antwort ist

Name

Straße, Nr.

PLZ, Ort

Was ich noch sagen wollte ...
Coupon bitte ausfüllen und abschicken an

Springer Medizin Verlag GmbH

Redaktion Im Focus Onkologie - Quiz 9/2017

Aschauer Straße 30, 81549 München

oder nehmen Sie online teil unter

www.springermedizin.de/im-focus-onkologie-quiz oder senden Sie uns eine E-Mail an kim.jene@springer.com oder senden Sie uns ein Fax an 089/20 304331113

Einsendeschluss: 12.10.2017

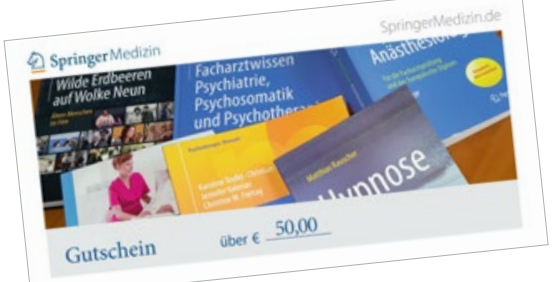

Das können Sie gewinnen!

Unter den richtigen Einsendungen verlosen wir drei Gutscheine über 50 Euro, die Sie für ein beliebiges Springer-Buch einlösen können.

Lösung des Quiz 06/2017: B

Die Gewinne gehen an:

H. Heinlein, Eschershausen, D. Drescher,

Wetzlar, M. Winter, Crailsheim 